Бычкова Гульфира Мубараковна, к.э.н., доцент, Ангарский государственный технический университет,

ОСОБЕННОСТИ ФОРМИРОВАНИЯ КЛЮЧЕВЫХ ПОКАЗАТЕЛЕЙ e-mail: gulfira_agta@mail.ru ЭФФЕКТИВНОСТИ В РОЗНИЧНОЙ ТОРГОВЛЕ

\title{
FEATURES OF THE FORMATION OF KEY INDICATORS EFFICIENCY IN RETAIL TRADE
}

\begin{abstract}
Аннотация. Разработаны ключевые показатели эффрективности, учитывающие специфику розничной торговли и повышающие качество обратной связи торговли с производством.

Ключевые слова: розничная торговля, ключевые показатели эффективности, мотивация, обратная связь.
\end{abstract}

Abstract. Key performance indicators have been developed that take into account the specifics of retail trade and improve the quality of feedback between trade and production.

Keywords: retail, key performance indicators, motivation, feedback.

Проблема, на решение которой направлено данное исследование, это выявление особенностей формирования ключевых показателей эффрективности (KPI) в розничной торговле. Актуальность определяется возможностью расширения сферы использования КРІ. Именно в розничной торговле формируется обратная связь производства с непосредственным потребителем. Для повышения объективности информации по потребительским характеристикам продукции, получаемой в торговле, можно использовать систему мотивации, снижающую уровень «помех» в системе обратной связи. Цель исследования - выявить и сформировать КРІ в розничной торговле, влияющие не только на мотивацию персонала, но и повышающие уровень качества обратной связи от потребителя к производителю. Задачи исследования: систематизировать сферы контроля расходов и доходов на стадиях закупки и реализации товара, возможные причины снижения качества обратной связи; разработать показатели КРІ в сфере закупки и реализации и рекомендации по формированию информационной базы для расчета КРІ. Объект исследования - система розничной торговли, предмет - фракторы, влияющие на мотивацию персонала и качество обратной связи системы розничной торговли с производителем.

К настоящему времени основные моменты разработки KPI определены [1]. С помощью системы KРІ оценивают эффективность деятельности работников. При этом ключевые показатели каждого сотрудника привязываются к стратегии компании и индикаторам бизнеса, таким как рентабельность, капитализация, прибыль. За выполнение показателей КРІ отвечает сам работник, от результата его работы зависит премия. Одним из основных индикаторов бизнеса является показатель рентабельности продаж, определяемый как отношение прибыли от продаж к выручке от продаж. Нам же необходимо учесть специфику 
розничной торговли. Поскольку весь процесс торговли «содержится» за счет торговой наценки, нами предлагается основной индикатор - показатель рентабельности процесса торговли, определяемый как отношение прибыли от продаж к покупной стоимости товара. Далее определяем, кто может контролировать показатели покупной стоимости, торговой наценки и выручки, участвующей в формировании прибыли от продаж. В своих рассуждениях мы используем следующее допущение - цену реализации принимаем за const, так как она задается рынком. Менеджер по закупкам может контролировать покупную стоимость товара и его качество, и, следовательно, он влияет на величину торговой наценки. Именно торговая наценка предлагается нами в качестве KPI для менеджера по закупкам. Менеджер по продажам контролирует показатель прибыли от продаж, рассчитываемый как «выручка от продаж минус коммерческие расходы». Выручка от продаж это произведение количества проданного товара на его цену. Первый показатель для менеджера по продажам - это количество продаваемого товара, второй - коммерческие расходы, связанные с продажами. В качестве обобщающего КРІ для менеджера по продажам предлагается показатель «Рентабельность процесса торговли», определяемый как отношение прибыли от продаж к покупной стоимости товара. Прибыль от продаж увеличивается с ростом объема продаж в натуральном измерении и снижением удельного веса коммерческих расходов в торговой наценке. Поэтому нами рекомендуются частные показатели КPI: «Количество проданного товара» и «Удельный вес коммерческих расходов в торговой наценке». Для получения необходимых исходных данных при расчете предлагаемых KPI в системе бухгалтерского учета рекомендуется ввести субсчета на счете 44 «Коммерческие расходы» для раздельного их учета на стадиях закупки и продажи. Причиной снижения качества обратной связи торговли с производством может являться несовершенная система мотивации персонала. Внедрение предлагаемых KPI позволит повысить удовлетворенность результатами труда и акцентировать внимание на анализе потребительских характеристик продукции и их влияния на объем продаж.

Таким образом, по результатам исследования для менеджера по продажам разработаны ключевой обобщающий показатель эффективности «рентабельность процесса торговли», частные показатели «количество проданного товара» и «удельный вес коммерческих расходов в торговой наценке», для менеджера по закупкам - показатель «торговая наценка», отличающиеся от имеющихся тем, что способствуют не только мотивации персонала, но и разделению сфер ответственности и повышению качества обратной связи системы розничной торговли с производством.

\section{ЛИТЕРАТУРА}

1. Кленова И. За что премировать сотрудников: наборы КРІ для подразделений компании». ФСС "Система Финансовый директор". Текст: электронный. - URL: https://www.1fd.ru/\#/document/16/44593/bss. 